\title{
Editorial
}

\section{Welcome to Seminars in Thrombosis \& Hemostasis 2022}

\author{
Emmanuel J. Favaloro, PhD, FFSc (RCPA) ${ }^{1}$ \\ ${ }^{1}$ Department of Haematology, Centres for Thrombosis and \\ Haemostasis, Institute of Clinical Pathology and Medical Research \\ (ICPMR), Westmead Hospital, Westmead, NSW, Australia
}

Semin Thromb Hemost 2022;48:1-2.

Welcome to the start of another year with Seminars in Thrombosis and Hemostasis (STH), this being my 14th year anniversary as Editor-in-Chief. As always, I wish to again sincerely thank all the contributors to STH over the years, as well as Guest Editors for past issues, and of course the current and past Editorial team. There has been no major overhaul of the editorial team at the time of writing, although some adjustments will continue to occur over the coming years.

I also take this opportunity to once again thank the journal production team at Thieme Medical Publishers for their high production standards and for facilitating both the print and online issues of the journal. In particular, I would like to thank Ankita Tripathi, the current Production Editor of the journal, and her production team, as well as Jessica Sieger, an Editor and Project Manager, for their ongoing support.

This now annual Editorial is usually the time that we reflect on our journal's Impact Factor. However, because of the continuing move to online publication ahead of the print publication, a separate detailed editorial was published late last year. ${ }^{1}$ In addition to detailing information on the journal's Impact Factor, in part in comparison to trends from other journals publishing in the Thrombosis and Hemostasis space, I also shared many other publication metrics.

I will summarize the information on Impact Factor as follows: (a) the 2020 Impact Factor for STH was 4.180, which marks a substantive increase over the 2019 Impact Factor, which was 2.892; (b) the 2019 Impact Factor, in turn, represented a significant decrease from our 2018 Impact Factor of 3.401; (c) in general, most thrombosis and hemo- stasis focused journals showed an increase in Impact Factor from 2019 to 2020 but showed a reduction in Impact Factor from 2018 to 2019. Thus, the 2020 Impact Factor appeared in part to have applied a kind of Impact Factor adjustment. It should also be noted that the calculations for Impact Factors are evolving to ensure better representation of online publications, which often precede print versions by several months. Indeed, some journals now only publish online. For the further interest of the readership, I have summarized the changes to the way the Impact Factor calculations are being generated in -Fig. 1. 2019 Impact Factors were calculated based on the publication of material in journal issues; 2020 transitioned to include online publications, and 2021 will reflect data using online publications.

As I always do for the Welcome Editorial, I confirm that we, as always, will continue to develop plans for the future content of this journal, and we are confident that Seminars will be able to continue to bring its readers the high-quality journal that is expected of us. Currently confirmed topics for issues that we plan to publish over the next 12 or so months are listed in - Table 1. Naturally, we recognize the need to retain some flexibility in our plans, and to potentially add additional material of current interest and controversy as the need arises. Notably, COVID-19 continues to create havoc for all of us, and this pandemic has led us to create a continuing series of issues specifically focused on thrombosis and hemostasis in COVID-19, 2,3 and now also including the current issue of the journal. Irrespective, we look forward to another interesting year of reading in 2022.

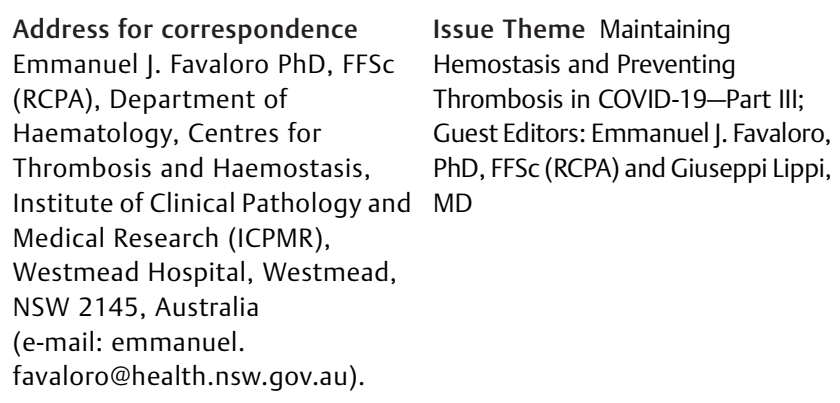

Address for correspondence Emmanuel J. Favaloro PhD, FFSc (RCPA), Department of Haematology, Centres for Thrombosis and Haemostasis, Institute of Clinical Pathology and MD Medical Research (ICPMR), Westmead Hospital, Westmead, NSW 2145, Australia (e-mail: emmanuel. favaloro@health.nsw.gov.au).

Issue Theme Maintaining Hemostasis and Preventing Thrombosis in COVID-19-Part III; Guest Editors: Emmanuel J. Favaloro, PhD, FFSc (RCPA) and Giuseppi Lippi,

(c) 2022. Thieme. All rights reserved. Thieme Medical Publishers, Inc., 333 Seventh Avenue, 18th Floor, New York, NY 10001, USA
DOI https://doi.org/ 10.1055/s-0041-1736167. ISSN 0094-6176. 
Impact Factor $2019=$

Impact Factor $2020=$

Impact Factor $2021=$
Citations in 2019 to papers published in issues $2017+2018$

Citable items published in issues $2017+2018$

\section{Citations in 2020 online publications* to papers published in issues $2018+2019$}

Citable items published in issues $2018+2019$

\section{Citations in 2021 online publications* to papers published online* $2019+2020$ Citable items published online* $2019+2020$}

\section{*if there is no online publication date, Clarivate will use the issue-publication date.}

Fig. 1 The evolution of the impact factor calculations, 2019 to 2021.

Table 1 Current planned topics for future issues of Seminars in Thrombosis \& Hemostasis include

\begin{tabular}{|l|}
\hline - Editorial compilations (continuing series). \\
\hline - Recent advances in thrombosis and hemostasis (continuing series). \\
\hline - Maintaining hemostasis and preventing thrombosis in COVID-19 (continuing series). \\
\hline - Laboratory diagnostics for thrombosis and hemostasis (continuing series). \\
\hline - Hemostasis in neurological injury-hemostasis and neuroscience. \\
\hline - Intrinsic (contact) coagulation/Inflammation. \\
\hline - Emerging use of viscoelastography in thrombosis and hemostasis: a challenge to conventional coagulation tests? \\
\hline - Optimizing and extending the risk adapted management of acute pulmonary embolism beyond the acute phase. \\
\hline - Platelets (and hemostatic effectors) in Precision Medicine. \\
\hline - Maternal and fetal thrombosis and hemostasis. \\
\hline
\end{tabular}

Conflict of Interest

None declared.

\section{References}

1 Favaloro EJ. Editorial. New STH (2020) Impact Factor, Most Highly Cited Papers, and Other Journal Metrics. Semin Thromb Hemost 2021;47:745-753
2 Favaloro EJ, Lippi G. Maintaining hemostasis and preventing thrombosis in coronavirus disease 2019 (COVID-19)-part I. Semin Thromb Hemost 2020;46(07):757-762

3 Favaloro EJ, Lippi G. Maintaining hemostasis and preventing thrombosis in coronavirus disease 2019 (COVID-19)-part II. Semin Thromb Hemost 2021;47(04):333-337 